\title{
Gender-Based Communication Styles, Trust, and Satisfaction in Virtual Teams
}

\author{
Kimberly Furumo \\ University of Hawaii at Hilo, \\ Hawaii, USA
}

furumo@hawaii.edu

\author{
J. Michael Pearson \\ Southern Illinois University at \\ Carbondale, IL, USA
}

jpearson@cba.siu.edu

\begin{abstract}
Previous studies have identified the difficulty of communicating in virtual teams. The lack of media richness, or opportunity for using non-verbal cues, leads to misunderstood communications and may limit the development of trust. Studies have also shown that males and females are socialized to communicate differently. Males use communication in teams to establish dominance and position while females use it to establish relationships and gain trust. In this study, we analyzed whether the gender of individual team members or the gender composition of the team impacted trust and satisfaction in short-duration virtual teams. Expectedly, females reported higher trust than males. However, team gender composition did not impact trust or satisfaction. The findings also indicate that males had less ability to dominate team interaction and that asynchronous computer mediated communication could equalize interactions among male and female team members.
\end{abstract}

Keywords: virtual teams, asynchronous computer mediated communication, gender, trust, satisfaction, female-homogeneous teams, male-homogeneous teams, gender-heterogeneous teams

\section{Introduction}

Advances in technology have changed the way many teams function. It is no longer necessary for teams to meet face-to-face with advances in technologies such as email, chat capabilities, video conferencing, and group support systems. Today's teams are composed of individuals who are often geographically dispersed and who come together and disband quickly depending upon the organization's needs. These teams use synchronous and asynchronous computer mediated communication and have often been referred to as virtual teams. The word virtual however, often causes confusion and researchers have struggled with its definition. For the purposes of this paper, we use the term "virtual team" to describe a short-duration distributed team that utilizes asynchronous computer mediated communication solely (we use the terms "short-duration virtual team" and "virtual team" interchangeably). We admit that our definition is somewhat short-sited

Material published as part of this publication, either on-line or in print, is copyrighted by the Informing Science Institute. Permission to make digital or paper copy of part or all of these works for personal or classroom use is granted without fee provided that the copies are not made or distributed for profit or commercial advantage AND that copies 1) bear this notice in full and 2) give the full citation on the first page. It is permissible to abstract these works so long as credit is given. To copy in all other cases or to republish or to post on a server or to redistribute to lists requires specific permission and payment of a fee. Contact Publisher@InformingScience.org to request redistribution permission. and results will refer to a small group of teams that fit this limited definition.

Previous studies have identified the difficulty of communicating in virtual teams because of the lack of media richness (Watson-Manheim \& Belanger, 2002). Many forms of computer mediated communication are more difficult because of the absence of nonverbal cues such as body language, gestures, 
and voice tone and inflection. The asynchronous nature of communications in virtual teams adds to the difficulty. Misunderstandings are more common and individuals working in virtual teams may be slower to develop trust in other members. When trust is absent, team members feel the need to double check each others' work and this increases transaction costs.

Since studies have shown that individuals have higher trust for members of their own demographic group (Keller, 2001; M. Williams, 2001), it is possible that gender composition in teams has an impact on performance. In this exploratory study, we analyze the effect of gender on trust and satisfaction in virtual teams and analyze whether individuals in gender-heterogeneous or gender-homogeneous teams experience higher trust and satisfaction.

\section{Literature Review}

Studies of virtual team effectiveness have identified the importance of trust. Trust has been defined as "the willingness of a party to be vulnerable to the actions of another party based on the expectation that the other will perform a particular action important to the trustor, irrespective of the ability to monitor or control that other party" (Mayer, Davis \& Schoorman, 1995). A lack of trust exists when one party does not have faith in the competencies of another or questions the motivation of the other to take the promised action as seriously (van der Smagt, 2000). So, trust can be seen as a relationship between two or more individuals in which one perceives that the others are involved, are competent, will complete their fair share of the work, and will make an honest effort to meet commitments.

Trust is important in teams because it lowers transaction costs (Watson-Manheim \& Belanger, 2002). Individuals, who do not trust fellow team members, are more likely to monitor or double check each other's work to insure the quality of the team's output. This self-protective activity increases the amount of time and resources needed to complete a project. In virtual teams, trust becomes an important component in preventing psychological distance (Snow, Snell \& Davison, 1996) and it increases confidence in relationships by promoting open information exchange (Jarvenpaa, Knoll \& Leidner, 1998). Trust is often referred to as the glue that holds the virtual team together.

Not surprisingly, trust has been identified as a determinant of effectiveness in virtual teams (Jarvenpaa \& Leidner, 1999; Sarker, Lau, \& Sahay, 2001; Walden \& Turban, 2000). Output produced by well-functioning teams should be superior to the output of any single individual since teams allow for better idea generation and the benefits of synergy that occur from multiple viewpoints. Individuals who trust each other are likely to be more satisfied with the team experience since they perceive that their best interests are being served, while only having to complete their fair share of the team's task. Reinig (2003) developed a scale for assessing satisfaction in virtual teams using group support system software and found that individual satisfaction with a team was related to how well the group handled problems and the extent to which the team's output reflected their individual input. Individuals who trust each other may be more likely to bring problems forth in an effort to resolve them effectively. Disagreements, when handled appropriately, have been found to have a positive impact on performance in traditional teams (Jehn, 1995).

Trust development in virtual teams may be more difficult in the absence of face-to-face contact (McDonough, Kahn, \& Barczak, 2001). Studies have identified the difficulty of communicating in virtual teams because of the lack of media richness (Watson-Manheim \& Belanger, 2002).

Computer mediated communication depersonalizes the interaction so there is a greater focus on the actual words in the message (Sproull \& Kiesler, 1991). If the communication only serves to report or inform, the possibility of misunderstanding may be low. But when communications go beyond simple reporting to task allocation and negotiation, the receiver may misinterpret the meaning of the message (van der Smagt, 2000). 
In addition, communicating in an asynchronous computer mediated environment electronically does not provide the same opportunity to build relationships as the face-to-face synchronous communication setting of the traditional team. In face-to-face teams, members are immediately aware of attributes of team members such as gender, age, and ethnicity. Before proceeding to the task of the team, members are likely to engage in social conversation based on similarities they perceive they have with other group members. In computer mediated teams, this initial social interaction is harder to initiate because members cannot easily perceive what they may have in common with others. So trust may be harder to develop in virtual teams because of the lack of media richness and the asynchronous nature of communications.

If communication impacts trust in teams, differences in communication styles among males and females may ultimately impact trust development in virtual teams. Numerous research studies have identified differences in male and female communication styles (Aries, 1996; Aries \& Johnson, 1983; Briton \& Hall, 1995; Burgoon \& Dillman, 1995; Dovidio, Brown, Heltman, Ellyson \& Keating, 1988; Holmes, 1995; Kette \& Konecni, 1995; LaFrance \& Henley, 1994; Rogers, 1989; Tannen, 1990a, 1990b; Troemel-Ploetz, 1991). When working with others, women's communication goals focus on gaining trust, developing consensus, and establishing relationships with others (Troemel-Ploetz, 1991). On the other hand, men's communication tends to be more taskoriented. Tannen (1990a) suggests that this may be the result of differences in socialization. Males are socialized to communicate in a "one-up, one down" style in which the goal is to win the discussion. Females, on the other hand, are socialized to communicate in a "rapport-talk" style in which the purpose is to discuss and understand others' perspectives.

In the absence of face-to-face synchronous interactions, how do virtual team members perceive trust? Since female's communication goals focus on gaining trust and establishing relationships (Troemel-Ploetz, 1991), their initial assumptions of trust in virtual teams may be greater than male's. If females value relationship building they may begin a team experience with the assumption that positive trusting relationships are not only possible but preferable. For males, relationship building seems to be less important except as it improves their ability to accomplish their goal. In this case, trust may seem less important to males. If this is the case, we would expect females to report higher levels of trust than males when working in short-duration virtual teams.

Research has also shown that females enjoy participating in virtual teams more than males (Berdahl \& Craig, 1996; Lind, 1999; Savicki, Kelley, \& Lingenfelter, 1996). Perhaps this is because it is more difficult for males to establish dominance through electronic communications. Males are more likely to use conversation as a method of gaining information and establishing status (Aries \& Johnson, 1983; Tannen, 1990b). Males have been found to assume dominance in relationships by utilizing verbal interruption (Aries, 1996). In the asynchronous computer mediated team, it may be more difficult to establish dominance without the ability to engage a team member's attention immediately. It is more difficult to interrupt communication and it may be more difficult to force another to view you as dominant. In this way, asynchronous computer mediated communication may have an equalizing effect on relationships.

If that is the case, females may report higher levels of trust in short-duration virtual teams because they are initially more trusting. Trust levels between males and females are likely to even out as the duration of the team expands and initial perceptions of trustworthiness are replaced with perceptions based on reality. Given these assumptions, the following hypothesis was developed.

Hypothesis 1: Females will report higher levels of trust and satisfaction than males working in short-duration virtual teams.

Studies have shown that individuals have higher trust for members of their own demographic group (Keller, 2001; M. Williams, 2001). Since teams are composed of multiple members, the 
impact of gender composition in the team may be important. Previous research has delivered mixed findings in terms of gender-homogeneous work groups and teams. Several studies suggest that job satisfaction is higher for individuals working in groups that are homogeneous for gender (Konrad, Winter \& Gutek, 1992; Tsui, Egan \& O'Reilly, 1992; Wharton \& Baron, 1991). Group cohesion has also been found to be lower in gender mixed groups (Fox, BenNahum \& Yinon, 1989; Jackson, Brett, Sess, Cooper, Julin \& Peyronnin, 1991; Kirchmeyer, 1995). And in their review of 40 years of research, K. Y. Williams and O'Reilly (1998) found that group process and performance were negatively impacted by the heterogeneous gender composition of groups.

Despite this strong base of research, Fields and Blum (1997), in their study of 1600 US workers, found that work group heterogeneity led to increased social interaction and more job satisfaction. And group gender diversity was also found to facilitate positive relationships between group efficacy and task performance and cohesion (Lee \& Farh, 2004).

One possible reason for these mixed findings could be the timeframe of the group experience. In the study performed by Fields and Blum (1997), semi-permanent work groups were studied. In the studies which uncovered the positive aspects of gender homogeneity, the focus was on temporary work teams. Therefore, gender homogeneity may have a more positive effect in teams that are together for a short duration of time while gender heterogeneity may enhance satisfaction in the long run. Therefore the following hypothesis was developed.

Hypothesis 2: In short-duration virtual teams, individuals in gender-homogeneous teams will report higher levels of trust and satisfaction than those in gender-heterogeneous teams.

Within the context of gender-homogeneous teams, it is likely that male-homogeneous and female-homogeneous teams will interact differently. Women focus to a greater extent on socialoriented activities while men focus on task-oriented activities (Dennis, Kinney \& Hung, 1999). Women's talk, more often then men's, is oriented toward maintaining relationships and developing intimacy with team members (Eakins \& Eakins, 1978). Females are more likely to express agreement or ask for others' opinions. They are also more likely than males to acknowledge points made by others at the beginning of their turn to speak, to provide nonverbal support for the speaker and to draw out the conversation of others (McConnell-Ginet, 1975; McLaughlin, Cody, Kane \& Robey, 1981). Females have also been found to work harder than males at facilitating conversation and encouraging follow-up talk (Fishman, 1983).

Men's communication in teams tends to be more competitive and is used to express dominance (Briton \& Hall, 1995; LaFrance \& Henley, 1994). Research shows that males use verbal interruption as a mechanism of power and dominance in conversations (Aries, 1996). In one study, interruption behavior increased among men in groups with higher proportions of males (Karakowsy, McBey \& Miller, 2004). These results suggest that males may be more competitive with other males when working in a team setting. This is not surprising given that research shows that men tend to value male input over female input and assume that men are more competent than women (Martin, 1996; Pierce, 1995; C. L. Williams, 1995).

Males are also more likely than females to intentionally withhold information to further their own positions or harm another's position (Deal, 2000). This action may hurt the team as a whole. Interdependence and cooperativeness in teams has been found to be related to constructive interchange (Tjosvold, 1988). And since females behave more cooperatively in negotiations than males (Walters, Stuhlmacher \& Meyer, 1998), female-homogeneous groups may be more effective than male-homogeneous groups.

Previous research related to gender-homogeneity in virtual teams is limited. However, women in female-only virtual teams reported more satisfaction with the team experience than men in male- 
only teams (Savicki et al, 1996). These female-only virtual teams also reported better team development. Therefore the following hypothesis was developed.

Hypothesis 3: In short-duration virtual teams, individuals in female-homogeneous teams will report higher levels of trust and satisfaction than those in male-homogeneous teams.

\section{Methodology}

\section{Design}

The hypotheses were tested using a quasi-experimental design in which participants were randomly assigned to three-member virtual teams to complete a week-long task. Participants in the study were upper level college students enrolled in a management course at a mid-sized university in the Midwestern United States and the task involved determining how to allocate \$1 million in surplus funds. At the conclusion of the experiment, individual students were given two surveys to complete. One measured the individual's perceived trust in the team and the other measured the individual's satisfaction with the team's outcome and process.

\section{Task}

The task used in this study was a preference task. Preference tasks are ambiguous in nature since there is no correct solution. The task required members to determine how to allocate $\$ 1$ million in surplus funds. Students were assigned one of three different roles: Chief Information Officer, Director of Operations, or Human Resources Director. Each character had a pressing need for use of the surplus funds and had to convince other team members that all or part of the money should be allocated to their department. There was no correct answer since all of the priorities were equally crucial for the company. To insure that students aggressively pursued the goals of the character they were playing in the project, they were told that $20 \%$ of their individual project grade would be based on their ability to get their funding objectives met and that they would receive a failing grade if the team choose to allocate the funds equally to each of their areas. The project accounted for $25 \%$ of each student's final grade.

\section{Tools and Manipulation Checks}

Students used WebCT, an instructional software package, to complete the team project. WebCT allows users to participate in email and discussion board facilities with assigned members of a team without divulging individual identities. Prior to the start of the experiment all participating students were trained on the WebCT software package. Students completed three assignments requiring them to use the various features of the software. All students who did not score a $100 \%$ on each assignment were required to re-do the assignment until they got perfect scores. This method provided assurance that each participant was familiar with the features of the WebCT software and that variations among participants in trust, satisfaction, and output were not the result of unfamiliarity with the technology.

In reality, many virtual team members have some face-to-face contact. However in this study, individuals in the virtual teams never met face-to-face and were instructed not to reveal any personal information about themselves during the course of the project. These participants were given a randomly generated email sign-on so other participants could not identify who their fellow team members were. On the day the project was assigned students were given a personalized printout, providing them with the WebCT email addresses of their team members and written instructions about how to complete the project. They were informed that they would receive a failing grade if they attempted to meet in person or communicate any personal information about themselves to the other team members. WebCT collects a stream of all communications that take 
place on-line and students were informed that the instructor would review the communication stream to insure that they did not violate the confidentiality guidelines. Review of the communication stream uncovered inappropriate communication in two teams and these individuals were eliminated from the study.

To further reduce unmeasured variability, students were eliminated from the study if they had had a previous virtual team experience or if one or more of the team members dropped the class before the completion of the experiment.

\section{Data Collection and Analysis}

To assess perceived trust levels, a scale developed by Jarvenpaa et al. (1998) was used. Their scale is based on previous instruments developed by Mayer et al. (1995) and Pearce, Sommer, Morris, and Frideger (1992) to measure the level of trust in dyads. Jarvenpaa et al. (1998) modified these instruments to reflect the team rather than a dyad by testing the two instruments at two different time points and across cultures. Both measures of trust were correlated but the instrument developed by Pearce and colleagues had higher reliability $(\alpha=.92)$ and thus it was used as the basis of their modified survey. After testing, Jarvenpaa et. al. (1998) reduced the 8-item scale to a 6-item instrument with a five-point Likert-type response scale anchored on one end with strongly agree and the other with strongly disagree. They reported Cronbach's alpha for the scale at .92 .

To measure individual satisfaction with the output and process of the team, a scale developed by Reinig (2003) was used. He developed and tested an instrument to measure satisfaction with group process and outcomes in the virtual and face-to-face team environments. His instrument consisted of five questions pertaining to satisfaction with the process and five pertaining to satisfaction with the decision. He reported Cronbach's alpha for the instrument at .79. Both instruments are included in the Appendix.

To test the hypotheses, ANOVA tests were performed. The independent variables were gender, and gender homogeneity/heterogeneity. The dependent variables measured in this study were trust and satisfaction. In addition, content analysis was performed on the communications logs supported by WebCT.

\section{Sample}

Of the original 114 students randomly assigned to teams, 12 were eliminated from the study because of one of the following reasons: either they or one of their team members dropped the class prior to the completion of the project, they or one of their team members had a previous virtual team experience, or they or one of their team members attempted to divulge their identify in the virtual team environment. The remaining sample consisted of 102 students ranging in age from 19 to 50 with a mean age of 22 years. Of the 102 students, 64 were male and 38 were female.

\section{Instrument Validation}

Before utilizing the scale data, principal components factor analyses were completed to insure that items appropriately tested the intended constructs. Analysis of the trust construct showed that all six items had acceptable loadings ranging from .712 to .865. All items were retained and the reliability analysis of the scale yielded a Cronbach's alpha of .87. A composite measure of trust was identified for each participant by averaging scores on the six items in the survey. Since the instrument utilized a 5-point Likert-type response scale, average scores could range from 1 for no trust to 5 for total trust. 
Analysis of the satisfaction construct yielded two distinct dimensions: outcome satisfaction and process satisfaction. The loadings for the first dimension ranged from .747 to .869 while the loadings for the second dimension ranged from .773 to .878. Two items related to outcome satisfaction were removed because of high cross-loadings. The overall reliability analysis yielded a Cronbach's alpha of .89. Composite measures for both dimensions of satisfaction were obtained by averaging the scores for each of the remaining items. These items were then averaged to arrive at an overall satisfaction composite. Since the instrument utilized a 5-point Likert-type response scale, average scores could range from 1 for total dissatisfaction to 5 for total satisfaction.

\section{Findings}

The ANOVA test for Hypothesis 1, which predicted that females would report higher levels of trust and satisfaction than males working in short-term virtual teams, partially confirmed the hypothesis. Results of the analysis (Table 1) show that males and females differ in terms of trust but not in terms of satisfaction. On average, females in the virtual teams reported trust at 3.89 while the men reported it at $3.61\left(\mathrm{~F}_{1,100}=3.140, \mathrm{p}=0.79\right)$.

\begin{tabular}{|l|c|c|c|}
\hline \multicolumn{4}{|c|}{ Table 1: Mean Trust and Satisfaction Levels in Virtual Teams } \\
\hline & Male & Female & Sig \\
\hline Trust & $3.61(.80)$ & $3.89(.71)$ & .079 \\
\hline Satisfaction & $3.76(.78)$ & $3.92(.75)$ & .308 \\
\hline
\end{tabular}

Hypothesis 2 stated that individuals in gender-homogeneous virtual teams would report higher levels of trust and satisfaction than those in gender-heterogeneous virtual teams. Table 2 shows that this hypothesis must be rejected. There were no significant differences in trust and satisfaction levels for individuals working in gender-homogeneous or gender-heterogeneous virtual teams. This indicates that team gender composition does not impact trust $\left(\mathrm{F}_{1,100}=800, \mathrm{p}=.373\right)$ or satisfaction $\left(\mathrm{F}_{1,100}=.031, \mathrm{p}=.860\right)$ in short-duration virtual teams.

\begin{tabular}{|c|c|c|c|}
\hline & Gender-Heterogeneous & Gender-Homogeneous & Sig. \\
\hline Trust & $3.76(.77)$ & $3.61(.80)$ & .373 \\
\hline Satisfaction & $3.81(.73)$ & $3.84(.73)$ & .860 \\
\hline
\end{tabular}

Hypothesis 3 proposed that individuals in female-homogeneous virtual teams would report higher levels of trust and satisfaction than those in male-homogeneous teams. Statistical test results, displayed in Table 3, showed that there were no significant differences in trust $\left(\mathrm{F}_{1,32}=.888, \mathrm{p}=\right.$ $.353)$ or satisfaction $\left(\mathrm{F}_{1,32}=.000, \mathrm{p}=.994\right)$ for individuals in male-homogeneous or femalehomogeneous teams. Therefore, Hypothesis 3 must be rejected. 


\begin{tabular}{|l|c|c|c|}
\hline \multicolumn{4}{|c|}{ Table 3: Mean Trust and Satisfaction Levels in Male-Homogeneous and } \\
Female-Homogeneous Virtual Teams \\
\hline & $\begin{array}{c}\text { Individuals in Male- } \\
\text { Homogeneous Teams }\end{array}$ & $\begin{array}{c}\text { Individuals in Female- } \\
\text { Homogeneous Teams }\end{array}$ & Significance \\
\hline Trust & $3.55(.80)$ & $3.89(.80)$ & .353 \\
\hline Satisfaction & $3.84(.79)$ & $3.84(.79)$ & .994 \\
\hline
\end{tabular}

Content analysis of WebCT-based communications logs revealed that both males and females made 22 contacts, on average, with other team members during the duration of the project (see Table 4). Male communication tended to be direct, task oriented, and frequently involved declarations of what the team member intended to do. Statements such as "I'll work up my numbers on a spreadsheet and you guys do the same" were common. Female communications, on the other hand, tended to be more polite and had a non-command nature to them. Statements such as "I think we should each work up a set of numbers on a spreadsheet and then we can compare results" were common. In addition, females tended to add statements such as "is everyone okay with that," or "I hope that works for everyone".

Males also reported more feelings of frustration in asynchronous computer mediated messages than females. Interestingly, these frustrations often led to an absence of future messages suggesting that these members stopped putting forth effort. Of the 64 males in the study, $8(12.5 \%)$ stopped corresponding after a frustrating message such as "This is stupid" or "This isn't working". Only two of the 38 females $(5.2 \%)$ had a similar reaction. This may suggest that females are more tolerant of ambiguity or become frustrated less easily when working in short-duration virtual teams.

Members in the all-male teams made an average of 25 asynchronous computer mediated contacts with other team members and spent approximately 6.2 hours to complete the project (Table 4). A large percentage of their members $(14.8 \%)$ were reported to be "deadbeats" (loafers) by the others and they earned the lowest scores on the project. The all-female teams had the least number of contacts (19) and spent the least amount of time to complete the project (5.5 hours). None of the team members were reported as deadbeats and these individuals earned the highest scores for the project. The gender-heterogeneous teams required the longest amount of time to complete the project, making more contacts than the female-homogeneous teams and less than the male homogeneous teams. These teams also reported a high number of deadbeats $(8.8 \%)$.

\begin{tabular}{|l|l|l|l|l|}
\hline \multicolumn{5}{|c|}{ Table 4: Performance Measures by Team Gender Composition } \\
\hline $\begin{array}{l}\text { Group Gender } \\
\text { Composition }\end{array}$ & $\begin{array}{c}\text { Average Number } \\
\text { of Computer } \\
\text { Mediated } \\
\text { Contacts }\end{array}$ & $\begin{array}{c}\text { Average Hours } \\
\text { required to } \\
\text { Complete the } \\
\text { Projects }\end{array}$ & $\begin{array}{c}\text { Percentage of } \\
\text { Deadbeat Team } \\
\text { Members }\end{array}$ & $\begin{array}{c}\text { Average Project } \\
\text { Grade }\end{array}$ \\
\hline All Male & 25 & 6.2 hours & $14.8 \%$ & $77 \%$ \\
\hline All Female & 19 & 5.5 hours & $0.0 \%$ & $88 \%$ \\
\hline $\begin{array}{l}\text { Male/Female } \\
\text { Mix }\end{array}$ & 22 & 6.5 hours & $8.8 \%$ & $79 \%$ \\
\hline
\end{tabular}




\section{Discussion}

Statistical tests for Hypothesis 1 confirmed that females were slightly more trusting than males in virtual teams. Female reported trust levels averaged 3.89 while male reported trust averaged 3.61. This finding does not reveal whether females tend to have a higher propensity to trust or whether there is some interaction in the virtual team which causes them to have higher trust levels than males. Previous research (Jarvenpaa \& Leidner, 1999; Myerson, Weick, \& Kramer, 1996) has indicated that in short-duration virtual teams, members assume trustworthiness initially and adjust their perceptions as the team proceeds. If this is the case, females may be more trusting initially than males. This would account for the slightly higher levels of trust among women.

Statistical tests for Hypotheses 2 and 3 did not reveal significant differences in trust and satisfaction for individuals working in gender-homogeneous or gender-heterogeneous virtual teams. Previous research has provided mixed findings of the impact of gender-homogeneity / heterogeneity on work group satisfaction. Gender-heterogeneity could negatively impact group cohesion and performance (Fox, et al, 1989; Jackson et al., 1991; Kirchmeyer, 1995; K. Y. Williams \& O'Reilly, 1998) as well as increase social interaction and job satisfaction (Fields \& Blum, 1997; Lee \& Farh, 2004).

While trust and satisfaction were not significantly different for individuals in genderheterogeneous and gender-homogeneous teams, the all-female teams completed the project quicker and better (see Table 4). Even without knowledge of the other team members' genders, there is some evidence that all-female teams may work together more effectively.

It is important to note that teams worked on a preference task in which there was no correct answer. Preference tasks require individuals to share information, discuss alternatives, and reach consensus on results. This requires open communication and interaction. Males may have attempted to express dominance but found it difficult because of the asynchronous nature of the communications. This would certainly explain why such a high number of males became deadbeats. Perhaps when realizing that their usual communication patterns were ineffective, these males withdrew from the team.

The strength of teamwork is in the synergy of ideas that are brought forth by alternative viewpoints. In virtual teams that communicate asynchronously, it seems that typical male communication patterns are less effective. It is more difficult for males to establish dominance through interruption behaviors when members control the preparation and delivery of messages. Asynchronous communications may make it easier for women to participate and express their points of view. Establishing dominance by males can be more difficult for two reasons. First, it is more difficult to interrupt other team members when communication takes place asynchronously. Second, it may be easier for females to express their point of view because they may take as much time as they need to formulate a response without being interrupted. As communication slows down, team members are able to process it more fully. Females may have an advantage here because their communication focuses on hearing different points of view and ensuring that all team members can express themselves. If this line of reasoning holds, it follows that asynchronous computer mediated communication may actually equalize interactions among male and female team members.

\section{Conclusions}

It should be noted that this study has several limitations. First, students were used as proxies in the study. While one review article of virtual team studies identified that $90 \%$ of published articles utilize student teams as research subjects (Powell, Piccoli, \& Ives, 2004), it is recognized that there may be difficulties generalizing these findings to other settings. Second, even though manipulation checks were put in place to insure that students worked in a pure asynchronous com- 
puter mediated communication environment, it is impossible to rule out the possibility that participants communicated outside the scope of the experiment.

In addition to the weaknesses mentioned above, it is important that readers realize that the findings in this study are generalizable only within the narrow scope in which this experiment was defined. For instance, teams in this experiment met for one week and findings would relate only to short-duration teams. The task that the teams worked on was a preference task in which there was no correct answer. For tasks that are straight forward and less ambiguous, findings may be different. Finally, in reality, virtual teams are often composed of members from different cultural backgrounds, who speak different languages, and live in different time zones. These factors are likely to impact trust and satisfaction in teams as well.

Despite its weaknesses, this study provides evidence that males may have less ability to dominate team interaction and females may be more influential in the asynchronous computer mediated virtual team. Put another way, our study suggests that asynchronous computer mediated communication may equalize interactions among male and female team members. In addition, while trust and satisfaction do not seem to be impacted by gender in short-term virtual teams, idea generation and output may be improved because of the asynchronous nature of computer mediated communication.

Future research should address how trust and satisfaction differ in long-duration versus shortduration virtual teams. Also, the impact of task type is important. Follow-up studies should analyze how trust and satisfaction are impacted when virtual teams work on an unambiguous task. Finally, the impact of asynchronous computer mediated communication on gender related communication needs to be analyzed.

\section{References}

Aries, E. (1996). Men and women in interaction: Reconsidering the difference. New York, NY: Oxford University Press

Aries, E., \& Johnson, F. (1983). Close friendship in adulthood: conversational content between same-sex friends. Sex Roles, 9 (11), 83-96.

Berdahl, J. \& Craig, K. (1996). Equality of participation and influences in groups: The effects of communication medium and sex composition. Computer Supported Cooperative Work, 4, 179-201.

Briton, N. J., \& Hall, J. A. (1995). Beliefs about female and male nonverbal communication. Sex Roles,32, 79-90.

Burgoon, J. K., \& Dillman, L. (1995). Gender, immediacy, and nonverbal communication. In P. J. Kalbfleisch \& M. J. Cody (Eds.), Gender, power and communication in human relationships (pp. 6381). Hillsdale, NJ: Erlbaum.

Deal, J. J. (2000). Gender differences in the intentional use of information in competitive negotiations. Small Group Research, 31, 702-23.

Dennis, A. R., Kinney, S. T., \& Hung, Y.-T. C. (1999). Gender differences in the effects of media richness. Small Group Research, 30, 405-437.

Dovidio, J. F., Brown, C. E., Heltman, K., Ellyson, S. L., \& Keating, C. F. (1988). Power displays between women and men in discussions of gender-linked tasks: A multi-channel study. Journal of Personality and Social Psychology, 55, 580-587.

Eakins, B. W., \& Eakins, R. G. (1978). Sex differences in human communication. Boston: Houghton Mifflin.

Fields, D. L., \& Blum, T. C. (1997). Employee satisfaction in work groups with different gender composition. Journal of Organizational Behavior, 18, 181-196. 
Fishman, P. M. (1983). Interaction: The work women do. In B. Thorne, C. Kramarae, \& N. Henley (Eds.), Language, gender, and society (pp. 89-102). Rowley, MA: Newbury House.

Fox, S., BenNahum, Z., \& Yinon, Y. (1989). Perceived similarity and accuracy of peer ratings. Journal of Applied Psychology, 74, 781-786.

Holmes, J. (1995). Women, men and politeness. Essex, England: Penguin.

Jackson, S. E., Brett, J. F., Sess, V. I., Cooper, D. M., Julin, J. A., \& Peyronnin, K. (1991). Some differences make a difference: Individual dissimilarity and group heterogeneity as correlates of recruitment, promotions, and turnover. Journal of Applied Psychology, 76, 675-689.

Jarvenpaa, S. L., Knoll, K., \& Leidner, D. E. (1998). Is anybody out there? Antecedents of trust in global virtual teams. Journal of Management Information Systems, 14, 29-64.

Jarvenpaa, S. L., \& Leidner, D. E. (1999). Communication and trust in global virtual teams. Organization Science, 10, 791-815.

Jehn, K. A. (1995). A multidimethod examination of the benefits and detriments of intragroup conflict. Administrative Science Quarterly, 40, 256-282.

Karakowsy, L., McBey, K., \& Miller, D. (2004). Gender perceived competence and power displays: Examining verbal interruptions in a group context. Small Group Research, 35, 407-439.

Keller, R. T. (2001). Cross-functional project groups in research and new product development: Diversity, communications, job stress, and outcomes. Academy of Management Journal, 44, 547-555.

Kette, G., \& Konecni, V. J. (1995). Communication channels and gender differences in decoding and integration of cues in legal decision making. In G. Davies, \& S. Lloyd-Bostock (Eds.), Psychology, law and criminal justice: international developments in research and practice (pp. 314-326). Berlin: de Gruyter.

Kirchmeyer, C. (1995). Demographic similarity to the work group: A longitudinal study of managers at the early career stage. Journal of Organizational Behavior, 16, 67-83.

Konrad, A. M., Winter, S., \& Gutek, B. A. (1992). Diversity in work group sex composition: Implications for majority and minority members. Research in the Sociology of Organizations, 10, 115-140.

LaFrance, M., \& Henley, N. M. (1994). On oppressing hypotheses: Or differences in nonverbal sensitivity revisited. In H. L. Radtke, \& H. J. Stam (Eds.), Power/gender: Social relations in theory and practice (pp. 287-311). London: Sage, Ltd.

Lee, C., \& Farh, J. L. (2004). Joint effects of group efficacy and gender diversity on group cohesion and performance. Applied Psychology: An International Review, 53, 136-154.

Lind, M. (1999). The Gender Impact of Temporary Virtual Work Groups. IEEE Transactions on Professional Communication, 42, 276-285.

Martin, P. Y. (1996). Men, masculinities and management: Gendering and evaluating dynamics. In D. L. Collinson, \& J. Hearn (Eds.), Men as managers, managers as men: Critical perspectives on masculinity (pp. 186-209). London: Sage, Ltd.

Mayer, R. C., Davis, J. H., \& Schoorman, F. D. (1995). An integrative model of organizational trust. Academy of Management Review, 20, 709-734.

McConnell-Ginet, S. (1975). Our father tongue: Essays in linguistic politics. Diacritics, 4, 44-50.

McDonough, E., Kahn, K., \& Barczak, G. (2001). An investigation of the use of global, virtual, and collocated new product development teams. The Journal of Product Innovation Management, 18, 110-120.

McLaughlin, M. L., Cody, M. J., Kane, M. L., \& Robey, C. S. (1981). Sex differences in story receipt and story sequencing behaviors in dyadic conversations. Human Communication Research, 7, 99-116.

Myerson, D., Weick, K.E., \& Kramer, R.M. (1996). Swift trust and temporary groups. In R.M. Kramer and T.R. Tyler (Eds.), Trust in organizations: Frontiers of theory and research (pp. 166-195). Thousand Oaks, CA: Sage Publications. 
Pearce, J. L., Sommer, S. M., Morris, A., \& Frideger, M. (1992). A configurational approach to interpersonal relations: Profiles of work place social relations and task interdependence. Irvine, CA: University of California.

Pierce, J. L. (1995). Gender trials: Emotional lives in contemporary law firms. Berkeley, CA: University of California Press

Powell, A., Piccoli, G., \& Ives, B. (2004). Virtual teams: A review of current literature and directions for future research. The Database for Advances in Information Systems, 35, 6-36.

Reinig, B. A. (2003). Toward an understanding of satisfaction with the process and outcomes of teamwork. Journal of Management Information System, 19, 65-83.

Rogers, D. B. (1989). Experimental studies of turn-taking behavior. In D. Roger, \& P. Bull (Eds.), Conversation: An interdisciplinary perspective. Philadelphia: Multilingual Matters.

Sarker, S., Lau, F., \& Sahay, S. (2001). Using an adapted grounded theory approach for inductive theory building about virtual team development. Database for Advances in Information System, 32, 38-56.

Savicki, V., Kelley, M., \& Lingenfelter, D. (1996). Gender, group composition, and task type in small task groups using computer-mediated communication. Computers in Human Behavior, 12, 549-565.

Snow, C. C., Snell, S. A., \& Davison, S. C. (1996). Use transnational teams to globalize your company. Organizational Dynamics, 24, 50-67.

Sproull, L., \& Kiesler, S. (1991). Connections: New ways of working in the networked organization. Cambridge, MA: MIT Press.

Tannen, D. (1990a). Gender differences in topical coherence: creating involvement in best friends' talk. Discourse Process, 13, 73-90.

Tannen, D. (1990b). You just don't understand: Women and men in conversation. New York: William Morrow.

Tjosvold, D. (1988). Cooperative and competitive interdependence: Collaboration between departments to serve customers. Group and Organization Studies, 13, 274-289.

Troemel-Ploetz, S. (1991). Review essay: Selling the apolitical. Discourse and Society, 2, 489-502.

Tsui, A., Egan, T., \& O'Reilly, C. (1992). Being different: Relational demography and organizational attachment. Administrative Science Quarterly, 37, 549-588.

van der Smagt, T. (2000). Enhancing virtual teams: Social relations vs. communication technology. Industrial Management \& Data Systems, 100.

Walden, P., \& Turban, E. (2000). Working anywhere, anytime and with anyone. Human Systems Management, 19, 213-222.

Walters, A. E., Stuhlmacher, A. F., \& Meyer, L. L. (1998). Gender and negotiator competitiveness: A meta-analysis. Organizational Behavior and Human Decision Processes, 76, 1-29.

Watson-Manheim, M. B., \& Belanger, F. (2002). Support for communication-based work processes in virtual work. e-Service Journal, 61-82.

Wharton, A. S., \& Baron, J. N. (1991). Satisfaction? The psychological impact of gender segregation on women at work. The Sociological Quarterly, 32, 365-387.

Williams, C. L. (1995). Still a man's world. Berkeley, CA: University of California.

Williams, K. Y., \& O'Reilly, C. (1998). Demography and diversity in organizations: A review of 40 years of research. In B. M. Staw, \& L. L. Cummings (Eds.), Research in organizational behavior (pp. 77 140), Greenwich, CT: JAI Press.

Williams, M. (2001). In whom we trust: Group membership as an affective context for trust development. Academy of Management Review, 26, 377-396. 


\section{Appendix}

The following instruments were used to measure trust and satisfaction in teams.

Trust (Source: Jarvenpaa, Knoll, \& Leidner, 1998)

1. Overall, the people in my group are very trustworthy $(1=$ strongly disagree, $5=$ strongly agree $)$

2. We are usually considerate of one another's feelings in this work group $(1$ = strongly disagree, $5=$ strongly agree $)$

3. The people in my group are friendly $(1=$ strongly disagree, $5=$ strongly agree $)$

4. There is no "team spirit" in my group $(1=$ strongly agree, $5=$ strongly disagree $)$

5. There is a noticeable lack of confidence among those with whom I work $(1=$ strongly agree, $5=$ strongly disagree $)$

6. We have confidence in one another in this group $(1=$ strongly disagree, $5=$ strongly agree $)$

Satisfaction (Source: Reinig, 2003)

With Outcome:

1. How satisfied or dissatisfied were you with the quality of your group's solution? ( 1 = very dissatisfied, $5=$ very satisfied)

2. To what extent does the final solution reflect your inputs? $(1=$ not at all, $5=$ to a very great extent $)$

3. To what extent do you feel committed to the group solution? $(1=$ not at all, $5=$ to a very great extent $)$

4. To what extent are you confident that the group solution is correct? $(1=$ not at all, $5=$ to a very great extent $)$

5. To what extent do you feel personally responsible for the correctness of the group solution?

$(1=$ not at all, $5=$ to a very great extent $)$

With Process:

6. How would you describe your group's problem solving process? $(1=$ very inefficient, 5 = very efficient $)$

7. How would you describe your group's problem solving process? ( $1=$ very uncoordinated, $5=$ very coordinated $)$

8. How would you describe your group's problem solving process? $(1=$ very unfair, 5 = very fair $)$

9. How would you describe your group's problem solving process? ( 1 = very confusing, 5 = very understandable $)$

10. How would you describe your group's problem solving process? ( $1=$ very dissatisfying, $5=$ very satisfying $)$

Items 1 and 5 were removed because of high cross loadings. 


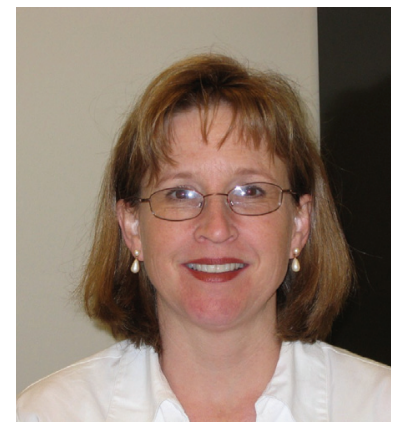

\section{Biographies}

Kimberly Furumo is an Assistant Professor of MIS at the University of Hawaii at Hilo. Her research interests include IS project management, virtual project teams, technology adoption, e-commerce, and human-computer interaction. Her work appears in the Communications of the ACM, the Journal of Computer Information Systems, the Interdisciplinary Journal of Information, Knowledge, and Management, the Journal of Information Technology Cases and Applications, the International Journal of Electronic Marketing and Retailing, the proceedings of the Hawaii International Conference on System Sciences, the Americas Conference on Information Systems, and the annual meeting of the Decision Sciences Institute. Prior to joining the faculty, Dr. Furumo worked in the business and IT areas.

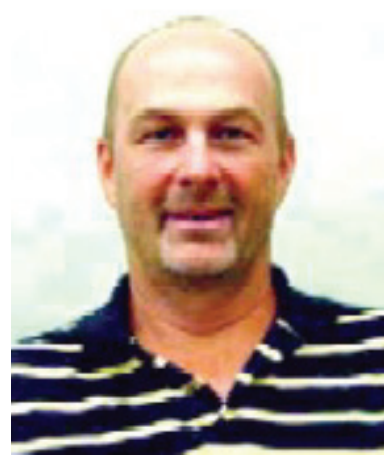

J. Michael Pearson is an Associate Professor of Information Systems at Southern Illinois University at Carbondale. Dr. Pearson currently serves as the editor for the Journal of Internet Commerce. Dr. Pearson has published over forty articles in journals such as the Communications of the ACM, Information \& Management, Journal of Strategic Information Systems, Journal of Information Systems, Journal of Computer Information Systems, Decision Support Systems, Review of Business, Information Resources Management Journal and Public Administration Quarterly. His research interests are in the areas of technology adoption, e-commerce, management of quality, and IT project management. 